\title{
Comparison of Sports Drink Versus Oral Rehydration Solution During Exercise in the Heat
}

\author{
Michael W. Schleh, MS; Charles L. Dumke, PhD \\ From the Department of Health and Human Performance, University of Montana, Missoula, MT.
}

Introduction-This study compared 2 commercially available beverages, an oral rehydration solution (ORS; $60.9 \mathrm{mM} \mathrm{Na}^{+} ; 3.4 \%$ carbohydrate) and a sports drink (SDS; $18.4 \mathrm{mM} \mathrm{Na}+; 5.9 \%$ carbohydrate), on hydration and metabolism during submaximal exercise in the heat.

Methods-Ten male subjects completed two 90-min exercise trials $\left(39^{\circ} \mathrm{C}, 30 \%\right)$ of walking at $50 \%$ $\mathrm{VO}_{2 \max }$ followed by a 30 -min rest period in the heat while wearing wildland firefighter personal protective clothing. After $45 \mathrm{~min}$ of exercise, fluid delivery by either ORS or SDS replaced $150 \%$ of sweat loss. Subjects continued the exercise for 45 additional minutes followed by a 30-min rest period. Blood samples were collected pre-exercise $(0 \mathrm{~min})$, post-exercise $(90 \mathrm{~min})$, and post-trial $(120 \mathrm{~min})$ to measure plasma volume $(\%)$ and blood glucose $\left(\mathrm{mg} \cdot \mathrm{dL}^{-1}\right)$. Expired gases were collected twice for $3 \mathrm{~min}$ for substrate oxidation.

Results-The sweat rate and percent dehydration did not differ between the groups $(P=0.86$ and $P=0.79$, respectively). Changes in plasma volume did not differ $(P=0.55)$. Hemoglobin levels significantly increased in both groups post-trial $(P=0.009)$. Blood glucose was significantly greater post-trial in SDS versus ORS $\left(116 \pm 19 \mathrm{vs} 103 \pm 13 \mathrm{mg} \cdot \mathrm{dL}^{-1}\right.$, respectively; $\left.P=0.01\right)$. Fat oxidation was lower post-exercise in SDS vs ORS $\left(0.38 \pm 0.1\right.$ vs $0.47 \pm 0.2 \mathrm{~g} \cdot \mathrm{min}^{-1}$, respectively; $\left.P=0.049\right)$.

Conclusions-These data indicate no difference in fluid retention between ORS or SDS when supplemented during exercise in the heat. This implies that fluid volume, and not drink contents, may be more important when ingested during exercise in a hot environment.

Keywords: wildland firefighter, hydration, rehydration, heat stress, fluid retention

\section{Introduction}

Prolonged exercise in the heat challenges individuals in maintaining fluid balance due to high rates of sweat loss, which can adversely affect exercise performance ${ }^{1-4}$ and thermal strain ${ }^{2,5}$ if fluid loss significantly exceeds fluid ingestion. To overcome environmental and metabolic heat accumulation and prevent hazardous elevations in core temperature $\left(\mathrm{T}_{\mathrm{c}}\right)$, sweating is necessary to thermoregulate. In sports and certain occupations (eg, wildland firefighters [WLFF] and military personnel), the amount of fluid lost by sweating varies with respect to both intrinsic (genetics, body size, and heat acclimation status) and extrinsic (environmental temperature/humidity, personal protective equipment, and exercise intensity/duration) factors. ${ }^{6}$

Corresponding author: Charles L. Dumke, $\mathrm{PhD}$, Department of Health and Human Performance, University of Montana. e-mail: charles.dumke@umontana.edu.

Submitted for publication July 2017.

Accepted for publication January 2018.
Hypohydration of approximately 3 to $4 \%$ has been shown to reduce plasma volume and thus challenge the cardiovascular system by decreasing stroke volume and cardiac output by approximately $13 \%$ while hyperthermic. ${ }^{7}$ The effect of graded dehydration also coincides with increases in $\mathrm{T}_{\mathrm{c}}$, an additional factor augmenting heat stress. ${ }^{5}$ Therefore, the American College of Sports Medicine's position on exercise and fluid replacement states that fluid intake during exercise should avoid body weight loss of $>2 \%$ to prevent hypohydration but also warns against excess drinking to avoid weight gain and risk of hyponatremia. ${ }^{6}$

Fluid volume and composition influence the rates of absorption from the stomach to the small intestine, allowing fluids to enter the extracellular space to help maintain plasma volume. ${ }^{8}$ Elevated sodium content of ingested fluids has been shown to significantly enhance fluid retention.? The presence of sodium in sports drink solutions (SDS) and oral rehydration solutions (ORS) not only enhances palatability and fluid retention but also stimulates the drive to drink. $^{9-11}$ Conversely, sodium concentrations that 
are too high $\left(>50 \mathrm{mmol} \cdot \mathrm{L}^{-1}\right)$ have been shown to decrease palatability, reduce the drive to drink, and possibly result in gastrointestinal distress in occupational athletes. ${ }^{12}$

Historically, ORS were designed to replace fluid and electrolyte losses at rest to prevent mortality associated with acute diarrheal illnesses. ${ }^{13,14}$ Consequently, the World Health Organization developed an ORS to aid in the recovery from acute diarrheal disease $\left(\mathrm{Na}^{+}=75\right.$ $\mathrm{mmol} \cdot \mathrm{L}^{-1} ; \mathrm{Cl}^{-}=65 \mathrm{mmol} \cdot \mathrm{L}^{-1} ; \mathrm{K}^{+}=20 \mathrm{mmol} \cdot \mathrm{L}^{-1}$; citrate $=10 \mathrm{mmol} \cdot \mathrm{L}^{-1}$; glucose $\left.=75 \mathrm{mmol} \cdot \mathrm{L}^{-1}\right) .{ }^{15} \mathrm{SDS}$ are typically designed to replace fluid and electrolyte losses from sweating during exercise and contain carbohydrate (CHO) to maintain work output for extended periods. ${ }^{11,16}$ Therefore, SDS typically contain approximately $60 \mathrm{~g} \cdot \mathrm{L}^{-1} \mathrm{CHO}, 20$ to $30 \mathrm{mmol} \cdot \mathrm{L}^{-1} \mathrm{Na}^{+}$, and 2 to $5 \mathrm{mmol} \cdot \mathrm{L}^{-1} \mathrm{~K}^{+}$. 6,11 Thus, these beverages were designed for different purposes under different situations, where ORS replaces fluid and electrolytes lost due to diarrhea and vomiting and SDS replaces fluid and electrolytes lost due to sweating from exercise.

Despite the intention of their formulations, ORS and SDS are often used in situations for which they are not intended. Only recently have attempts been made to directly compare different formulations of drinks on measures of hydration. In one study, although subjects were euhydrated and at rest, ORS and, surprisingly, milk resulted in the least amount of urine output and thus the greatest fluid retained. ${ }^{17}$ However, no studies have directly compared ORS and SDS during exercise.

The optimal composition of a fluid replacement drink has been suggested to depend on the mechanism of fluid loss (sweat, urine, respiration, or diarrhea/vomiting); therefore, drink compositions are best customized to the specific situation. ${ }^{11,17}$ Despite these recommendations, data that compare the effectiveness of ingesting an ORS versus SDS during exercise in the heat do not exist.

Military personnel and WLFF are exposed to several factors that affect heat stress throughout the day, such as high ambient temperature, personal protective equipment,
Table 1. Participant characteristics

\begin{tabular}{lc}
\hline Characteristic & Mean $\pm S D$ \\
\hline Age $(\mathrm{y})$ & $22.5 \pm 4.0$ \\
Weight $(\mathrm{kg})$ & $82.2 \pm 10.1$ \\
Height $(\mathrm{cm})$ & $182 \pm 9$ \\
Body fat $(\%)$ & $14 \pm 5$ \\
$\mathrm{VO}_{2 \text { max }}\left(\mathrm{mL} \cdot \mathrm{kg}^{-1} \cdot \mathrm{min}^{-1}\right)$ & $53.9 \pm 5.9$ \\
\hline
\end{tabular}

and added metabolic heat due to high-energy demands. ${ }^{18,19}$ Previous studies of WLFF have reported water turnover as high as 7 to $9 \mathrm{~L} \cdot \mathrm{day}^{-1}$. $^{18,20}$ With such high water turnover mostly due to sweat loss, hydration strategies involving appropriate sodium and $\mathrm{CHO}$ supplementation are critical to meet fluid losses and provide $\mathrm{CHO}$ for both safety and sustained work output.

The purpose of this study was to compare the effect of a single bolus of an ORS versus SDS beverage on hydration during exercise in the heat. The results would allow for better-informed decisions in the provision of fluids for the safety and performance of athletes, military and WLFF personnel, and others who exercise in the heat.

\section{Methods}

\section{SUBJECTS}

Ten aerobically fit adult males volunteered to participate in this study (Table 1). Before testing, each subject agreed to and signed an informed consent form approved by the University of Montana Institutional Review Board (167-16).

\section{EXPERIMENTAL DESIGN}

One week after preliminary testing, all participants $(n=10)$ completed 2 exercise trials in a climate-controlled heat chamber $\left(39^{\circ} \mathrm{C} ; 30 \%\right)$ for $90 \mathrm{~min}$ at $50 \% \mathrm{VO}_{2 \max }$ (Figure 1). Subjects were instructed to not exercise for

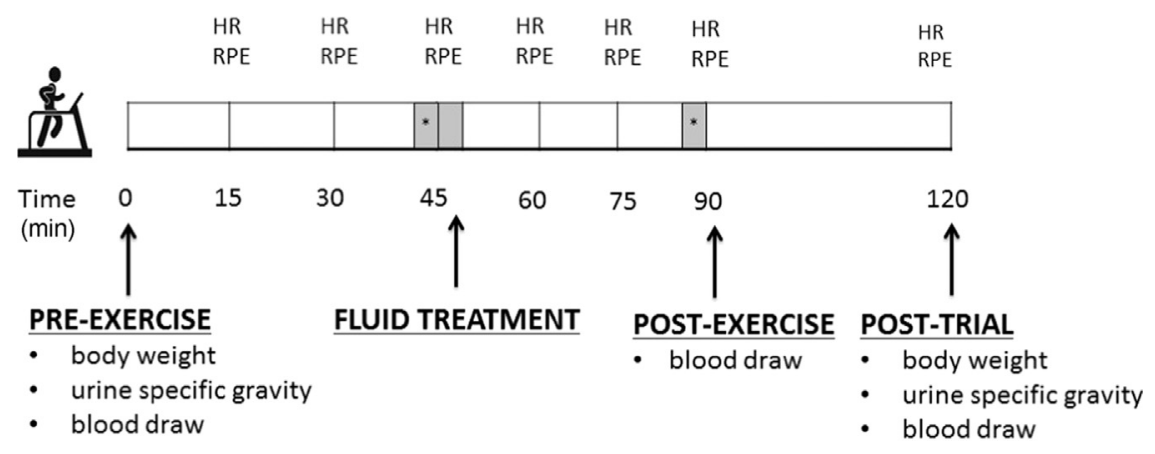

Figure 1. Schematic of study. *Metabolic gas measurement (3 min). 
Table 2. Fluid contents for SDS and ORS beverages

\begin{tabular}{lcr}
\hline & SDS & ORS \\
\hline Osmolarity $\left(\mathrm{mOsm} \cdot \mathrm{L}^{-1}\right)$ & 355 & 235 \\
Sodium $\left(\mathrm{mg} \cdot \mathrm{L}^{-1}\right)$ & 458 & 1330 \\
Potassium $\left(\mathrm{mg} \cdot \mathrm{L}^{-1}\right)$ & 125 & 780 \\
Citrate $\left(\mathrm{mEq} \cdot \mathrm{L}^{-1}\right)$ & $\mathrm{N} / \mathrm{A}$ & 160 \\
Magnesium $\left(\mathrm{mg} \cdot \mathrm{L}^{-1}\right)$ & 0 & 166 \\
Zinc $\left(\mathrm{mg} \cdot \mathrm{L}^{-1}\right)$ & 0 & 6 \\
Carbohydrate $\left(\mathrm{g} \cdot \mathrm{L}^{-1}\right)$ & 59 & 33 \\
Calories $\left(\mathrm{kcal} \cdot \mathrm{L}^{-1}\right)$ & 236 & 135 \\
\hline
\end{tabular}

ORS, oral rehydration solution; SDS, sports drink solution.

$24 \mathrm{~h}$ before the experimental trials, to avoid alcohol, and to repeat the same diet and liquid intake the day before the trials. During each trial, subjects consumed a single bolus of either a commercially available SDS (Gatorade Thirst Quencher, Pepsico, Barrington, IL; Table 2) or a commercially available ORS (DripDrop, Oakland, CA; Table 2) $45 \mathrm{~min}$ into the 90-min exercise bout. Subjects wore standard-issue heat-and-flame resistant Nomex WLFF personal protective shirts and pants with a cotton t-shirt base layer and comfortable shoes and socks for both trials.

Fluid delivery was prescribed at $150 \%$ of each subject's sweat loss from the initial 45 min of exercise. ${ }^{9}$ Either ORS or SDS were delivered in a double-blind, random, crossover design. At min 45 of exercise, subjects rested for $10 \mathrm{~min}$, during which nude weight was recorded and the appropriate fluids were delivered (SDS or ORS) while sitting in the heat chamber. Heart rate (HR) and rating of perceived exertion (RPE) using the 6-20 scale ${ }^{21}$ was collected every 15 min during the 90-min trials. After the 90-min exercise bout, subjects rested while sitting for $30 \mathrm{~min}$ in the heat. Respiratory measurements for ventilation $\left(\mathrm{V}_{\mathrm{E}}\right), \mathrm{VO}_{2}$, and $\mathrm{VCO}_{2}$ were included to estimate substrate utilization. Steady-state expired gases were obtained for $3 \mathrm{~min}$ at time periods before the 45-min (mid-exercise) and 90-min time points (post-exercise). Blood samples from finger capillary punctures were obtained pre-exercise, post-exercise, and post-trial after $5 \mathrm{~min}$ of sitting steady state (Figure 1). All trials were completed during the months of October and November in Missoula, Montana, $\left(46.9^{\circ}\right.$ $\mathrm{N})$ to reduce any confounding seasonal acclimation.

\section{PRELIMINARY TESTING}

After providing informed consent, subjects completed a physical activity readiness questionnaire (PARQ) to assess cardiovascular disease factors and prevent potential complications. Subjects who answered "yes" to any questions were excluded from the study. Subjects were also excluded if they regularly used saunas or hot tubs or traveled to warmer climates.

\section{BODY COMPOSITION}

Body density was determined using the hydrodensitometry method and corrected for estimated residual lung volume. $^{22}$ A minimum of 3 underwater weights were collected using a load-cell tank (Exertech, Dresbach, $\mathrm{MN}$ ). Body density was then converted to body composition using Siri Equation. ${ }^{23}$

\section{AEROBIC FITNESS}

Participants completed a graded exercise test to exhaustion on a treadmill (Fullvision, Inc., Newton, KS) using the Bruce Protocol. ${ }^{24}$ To measure $\mathrm{VO}_{2 \text { max }}$, expired gases were collected and averaged every $15 \mathrm{~s}$ via a metabolic cart (Parvomedics, Inc., Sandy, UT). To reach $\mathrm{VO}_{2 \max }, 3$ of the following criteria had to be met: 1) plateau in $\mathrm{VO}_{2}$ despite an increased workload, 2) respiratory exchange ratio $>1.10,3) \mathrm{HR}$ within 10 beats. $\mathrm{min}^{-1}$ of subjects' predicted $\mathrm{HR}_{\max }$, and 4) RPE $>17$ before exhaustion as determined via the $6-20$ scale. $^{21}$

\section{BLOOD ANALYSIS}

Blood samples were collected with heparinized capillary tubes (Kimble Chase, Rockwood, TN) using a $2.3 \mathrm{~mm}$, 18-gauge lancet (Medipurpose, Duluth, GA) from a capillary finger sample. Hematocrit was immediately measured in triplicate after centrifugation at $12000 \mathrm{~g}$ for 6 min (Graham Field, Atlanta, GA). Hemoglobin was immediately measured in triplicate and analyzed from a dual wavelength $(570 \mathrm{~nm}$ and $880 \mathrm{~nm})$ hemoglobin portable photometer (HemoCue, Brea, CA). Plasma volume was calculated by the assessment of hematocrit and hemoglobin and corrected for hemoconcentration, as explained by Dill and Costill. ${ }^{25}$ Blood glucose concentration was analyzed in duplicate from a portable glucose monitoring system (Lifescan Inc., Milpitas, CA).

\section{FLUID BALANCE}

Percent dehydration was calculated from the change in pre-exercise, mid-exercise, and post-trial nude body weights (Figure 1). Sweat rate $\left(\mathrm{L} \cdot \mathrm{h}^{-1}\right)$ was calculated from the change in pre-trial, mid-exercise, and post-trial nude body weights and corrected for urine excretion, fluid consumed, and respiratory water $\operatorname{loss}^{26}$ :

sweat rate $\left(\mathrm{L} \cdot \mathrm{h}^{-1}\right)=\left[\left(\mathrm{BW}_{\text {pre }}+\right.\right.$ fluids consumed $)$ $-\left(\mathrm{BW}_{\text {post }}+\right.$ urine + resp water loss $\left.)\right] / \mathrm{h}$ 

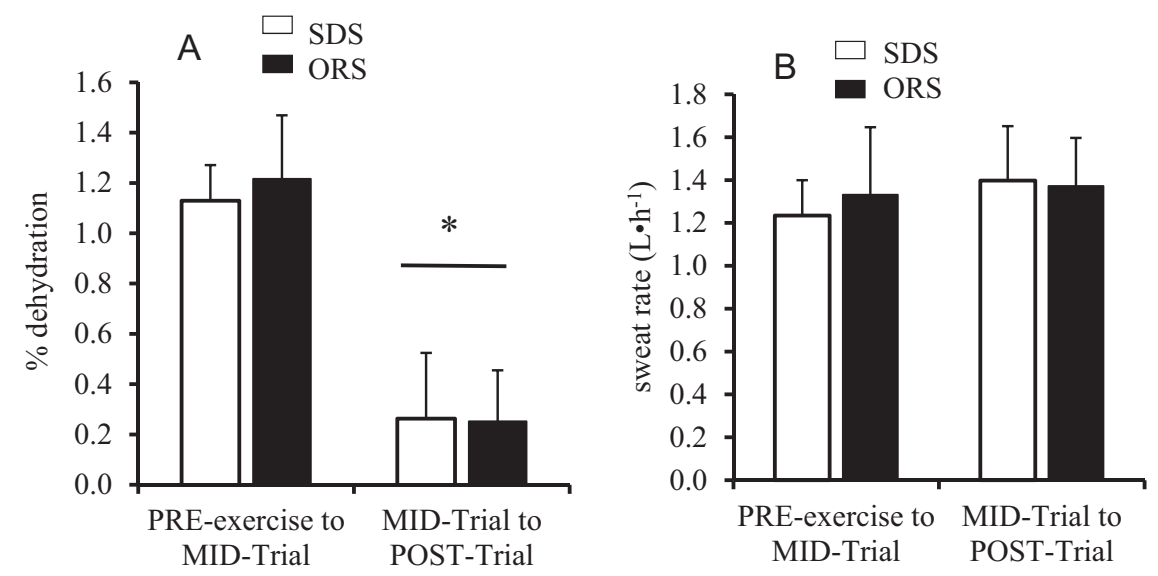

Figure 2. A, Percent dehydration (\%). B, Sweat rate $\left(\mathrm{L} \cdot \mathrm{h}^{-1}\right)$. Mean \pm SD. *Significant effect of time $(P<0.001)$.

Urine was collected pre- and post-trial to determine the amount of fluid retained throughout the exercise bout (urine volume, $\mathrm{mL}$ ), as well as urine specific gravity.

\section{SUBSTRATE UTILIZATION}

Fat and $\mathrm{CHO}$ oxidation were determined from gas exchange via indirect calorimetry. Substrate utilization was determined from $\mathrm{VO}_{2}\left(\mathrm{~L} \cdot \mathrm{min}^{-1}\right)$ and $\mathrm{VCO}_{2}\left(\mathrm{~L} \cdot \mathrm{min}^{-1}\right)$ 3 min prior to the end of the mid- and post-exercise time periods using the following equations, assuming that protein oxidation was negligible ${ }^{27}$ :

$$
\mathrm{CHO}\left(\mathrm{g} \cdot \mathrm{min}^{-1}\right) \text { oxidation }=4.21 \cdot \mathrm{VCO}_{2}+2.962 \cdot \mathrm{VO}_{2}
$$

Fat oxidation $\left(\mathrm{g} \cdot \mathrm{min}^{-1}\right)=1.695 \cdot \mathrm{VO}_{2}+1.701 \cdot \mathrm{VCO}_{2}$

\section{STATISTICS}

Dependent variables were analyzed by 2 -way $(2 \times 3)$ analysis of variance (ANOVA, TrtXTime). Fluid balance (sweat rate and percent dehydration), as well as urine specific gravity, urine volume, plasma volume, and substrate utilization, were analyzed using a 2-way ANOVA (2x2) at the time points described previously. All data were analyzed using SPSS for Windows, version 24 (SPSS, Chicago, IL). Statistical significance was set at $P<0.05$. All data are reported as mean \pm SD.

\section{Results}

Percent dehydration was not significantly different between the trials from pre- to mid-exercise $(P=0.79$; Figure 2A) prior to the intervention. However, percent dehydration was significantly lower at the mid- to posttrial measurement in both treatment groups after a bolus fluid ingestion that equated to $150 \%$ sweat loss
$(P<0.001)$ at mid-exercise. There was no significant effect of treatment, nor an interaction on percent dehydration $(P=0.80)$. Sweat rate was not statistically different between SDS and ORS ( $P=0.86$; Figure 2B). Urine specific gravity did not differ between SDS and ORS from pre-exercise to post-trial (pre-exercise: 1.018 \pm 0.006 and $1.023 \pm 0.006$, respectively; $P=0.14$ ) or have an effect of time (post-trial: $1.022 \pm 0.022$ and 1.019 \pm 0.022 , respectively; $P=0.86$ ). Urine volume was not statistically different from pre-exercise to post-trial between SDS and ORS $(111 \pm 176$ and $71 \pm 57 \mathrm{~mL}$, respectively; $P=0.50$ ).

Hemoglobin levels significantly increased from postexercise to post-trial for both treatment groups $(P=0.009$; Table 3$)$. Post hoc analysis indicated that hemoglobin levels significantly increased from mid- to post-exercise in both SDS and ORS $(P=0.002)$. Hematocrit did not demonstrate significant effects of time $(P=0.55)$, treatment $(P=0.43)$, or interaction $(P=0.74)$. The change in plasma volume demonstrated a significant effect of time $(P=0.01)$ and treatment $(P=0.01$; Table 3$)$. Post hoc analysis demonstrated that treatments were different post-exercise $(P=0.003)$ but not post-trial $(P=0.07)$.

HR significantly increased over time for both SDS and ORS $(P<0.001)$ but was not different between SDS or ORS ( $P=0.85$; Figure $3 \mathrm{~A})$. RPE significantly increased from pre- to post-exercise $(P=0.002)$ but did not differ between SDS and ORS ( $P=0.21$; Figure $3 \mathrm{~B})$. However, RPE was significantly lower at rest in SDS compared with ORS at min 15 and 30 post-exercise (TrtXTime; $P=0.015$; Figure 3B).

There was both a significant effect of time $(P=0.001)$ and an interaction $(P=0.013)$ on blood glucose (Figure 4). Post hoc analysis indicated that blood glucose increased to a greater extent in SDS compared 
Table 3. Blood data for 10 subjects received pre-exercise, post-exercise, and post-trial (mean \pm SD)

\begin{tabular}{|c|c|c|c|c|c|c|}
\hline & \multicolumn{3}{|c|}{$S D S$} & \multicolumn{3}{|c|}{ ORS } \\
\hline & Pre-exercise & Post-exercise & Post-trial & Pre-exercise & Post-exercise & Post-trial \\
\hline Hemoglobin $\left(\mathrm{g} \cdot \mathrm{dL}^{-1}\right)$ & $16.1 \pm 1.3$ & $15.7 \pm 1.0$ & $16.2 \pm 1.1^{a}$ & $15.4 \pm 1.4$ & $15.3 \pm 1.0$ & $16.3 \pm 1.4^{a}$ \\
\hline Hematocrit $(\%)$ & $48.4 \pm 3.4$ & $48.5 \pm 4.1$ & $48.7 \pm 4.1$ & $47.9 \pm 3.0$ & $47.8 \pm 3.3$ & $48.5 \pm 4.1$ \\
\hline $\begin{array}{l}\text { Change in plasma } \\
\text { volume }(\%)\end{array}$ & - & $2.2 \pm 6.3$ & $-1.5 \pm 6.5$ & - & $-2.4 \pm 6.5$ & $-5.3 \pm 11.2$ \\
\hline
\end{tabular}

ORS, oral rehydration solution; SDS, sports drink solution.

${ }^{a}$ Significant effect of time $(P<0.05)$

with ORS post-trial ( $P=0.019$; Figure 4$)$. CHO oxidation significantly increased in SDS and ORS post-exercise over time $(P=0.013$; Figure 5A). A significant interaction (TrtXTime; $P=0.04$ ) was found for fat oxidation (Figure 5B). Post hoc analysis found that fat oxidation was significantly greater post-exercise in ORS compared with SDS $(P=0.049)$.

\section{Discussion}

These data suggest that ORS and SDS are similar in their ability to maintain hydration during a bout of exercise in the heat when supplemented with adequate volume ( $>150 \%$ sweat loss). Markers of hydration in this study showed no treatment difference between hematocrit, hemoglobin, urine specific gravity, or urine produced over the 2-h trial. Neither percent dehydration nor sweat rate differed between the groups from mid-exercise (45 $\mathrm{min})$ to post-trial $(120 \mathrm{~min})$ after fluid ingestion. These results agree with those from previous studies that showed no difference in body weight change or sweat rate with or without sodium supplementation during exercise. $^{28}$

The rationale of the current study in the delivery of $150 \%$ of fluid loss bolus is based on previous evidence in the literature as well as external validity. It is recommended that the amount of fluid ingested be greater than what is lost to maintain fluid balance in the heat. ${ }^{9,29}$ Also, occupations such as WLFF are less likely to have the frequent breaks for hydration (approximately every 10-15 $\mathrm{min}$ ) that are often used in research studies. Importantly, this study also aimed to challenge the ability of subjects to retain the delivered fluids. Previous evidence has demonstrated that the sodium content of ingested fluids is an important consideration for fluid retention after exercise. ${ }^{9,29}$ However, evidence is less clear during exercise. One study showed that sodium delivered $\left(900 \mathrm{mg} \cdot \mathrm{h}^{-1}\right)$ during a 2-h bout of exercise exhibited no difference in thermoregulation, cardiovascular drift, or aerobic performance (measured in subsequent time trial to exhaustion) compared with placebo. $^{28}$

Although not measured in the current study, it is well established that exercise stimulates the release of the antidiuretic hormones aldosterone and vasopressin. ${ }^{30,31}$ The results of this study and others ${ }^{28,30,31}$ suggest that the elevation of these antidiuretic hormones associated
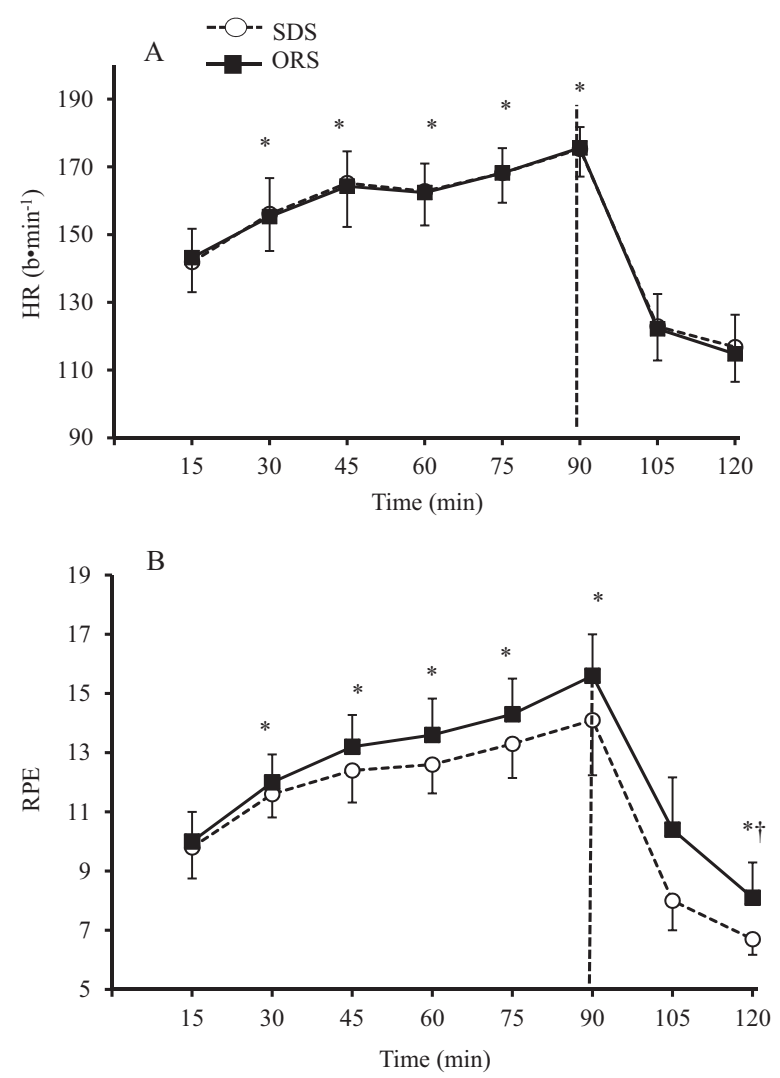

Figure 3. A, Heart rate and B, rating of perceived exertion throughout the 90-min exercise trial and 30-min rest period. Mean \pm SD. - - Exercise to rest transition. * Significant effect of time $(P<0.05)$, ${ }^{\dagger}$ Significant effect of TrtXTime $(P=0.013)$. 


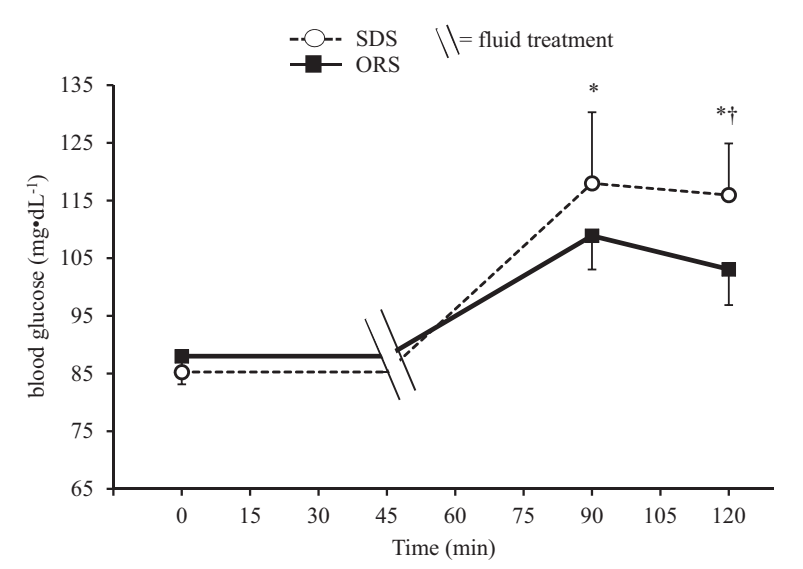

Figure 4. Blood glucose collected pre-exercise (0 min), post-exercise (90 min), and post-trial (120 min). Mean \pm SD. *Significant effect of time $(P=0.001)$. ${ }^{\dagger}$ Significant effect of TrtXTime $(P=0.013)$.

with increased plasma osmolality during exercise appears to supersede the approximate 3-fold difference in sodium content of the ORS and SDS on fluid retention. This suggests that, when considering hydration strategies concurrent with exercise in the heat, fluid volume is more important than modest differences in the content of the beverages when combined with the antidiuretic effects of these hormones.

The time and treatment effect on plasma volume (Table 3) may be due to the high individual variability in response to fluid ingestion, as well as the fluid compartment changes with body position and exercise. The significant time effect of the $30 \mathrm{~min}$ of sitting between post-exercise and post-trial on plasma volume is most likely due to fluid compartment shifts because the subjects did not ingest fluids during this time. The loss of muscle contraction from walking and change in body position (upright to sitting) demonstrated a loss of plasma volume, perhaps as fluid shifts into the interstitium. Indeed, post hoc analysis demonstrated that ORS and SDS were only significantly different at the post-exercise time point $(P=0.003)$, not post-trial $(P=0.07)$. The cause for the time and treatment effect appears to result from the apparent plasma volume expansion during the SDS trial post-exercise. Whether this is a true treatment effect or a result of criticisms of the technique to estimate changes in plasma volume using the Dill and Costill method remains to be seen.

These data do support the importance of identical body position, and enough time for fluid compartment shifts to normalize, prior to bloodletting in estimating changes in plasma volume using the Dill and Costill method. Nonetheless, this randomized, double-blinded, crossover design that included consistent bloodletting procedures across trials suggests a true treatment effect. Of the 9 subjects for whom we have complete blood data, 5 subjects during the SDS trial had a plasma volume that expanded post-exercise, whereas only 2 subjects in the ORS trial did.

Sodium replacement from sweat loss is another consideration during exercise in the heat. Sweat sodium concentration is highly variable due to genetic factors, diet, body weight, and acclimation, which influences the amount of sodium necessary to replace what is lost. ${ }^{6}$ Despite the large interindividual variability in sweat sodium, normative data from a wide range of athletes have been predicted to be $35.9 \pm 10.4 \mathrm{mmol} \cdot \mathrm{L}^{-1} \cdot 32,33$ On this basis, in the current study, the predicted sodium loss for the total 120-min trials would have been $2.1 \mathrm{~g}$. The delivery of ORS and SDS resulted in 1.9 and

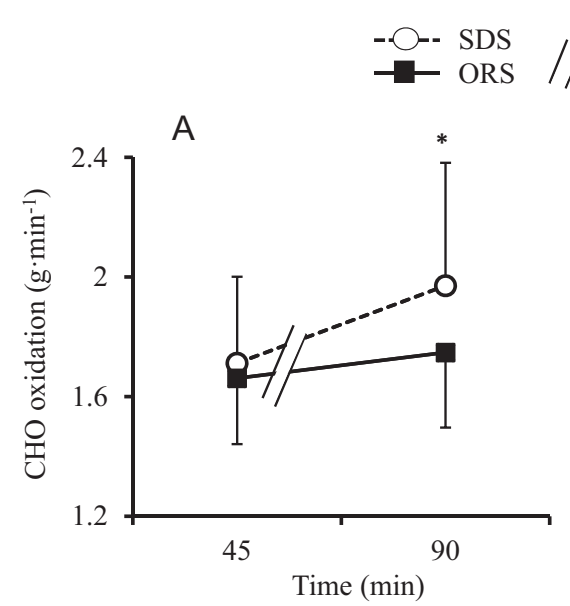

$/ /=$ fluid treatment

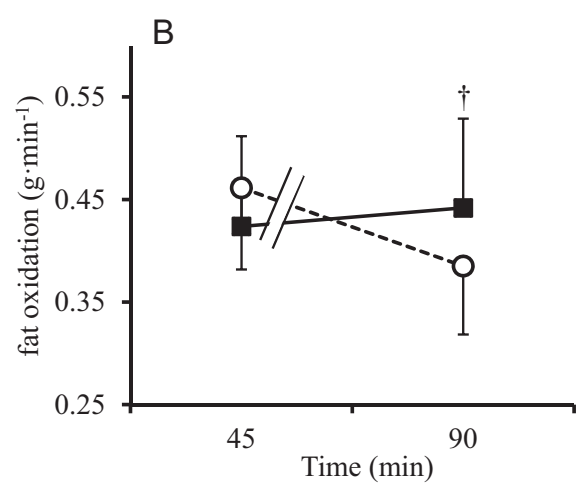

Figure 5. A, Carbohydrate oxidation $\left(\mathrm{g} \cdot \mathrm{min}^{-1}\right)$ and $\mathrm{B}$, fat oxidation $\left(\mathrm{g} \cdot \mathrm{min}^{-1}\right)$ collected from respiratory gas exchange during exercise prior to fluid ingestion $(45 \mathrm{~min})$ and after fluid ingestion $(90 \mathrm{~min})$. Mean \pm SD. $*$ Significant effect of time $(P=0.013)$. ${ }^{\dagger}$ Significant effect of TrtXTime $(P=0.049)$. 
$0.7 \mathrm{~g}$ sodium, respectively. Thus, neither drink exceeded the predicted sodium losses, but again, these differences in sodium delivery did not appear to affect fluid retention.

Sodium content of fluids can also affect palatability. One field study involving WLFF who consumed a water + electrolyte beverage $\left(22.8 \mathrm{mmol} \cdot \mathrm{L}^{-1}: \mathrm{Na}^{+}=125 \mathrm{mg} \cdot \mathrm{L}^{-}\right.$ ${ }^{1} ; \mathrm{K}^{+}=130 \mathrm{mg} \cdot \mathrm{L}^{-1} ; \mathrm{Mg}^{2+}=45 \mathrm{mg} \cdot \mathrm{L}^{-1} ; \mathrm{Cl}=390 \mathrm{mg} \cdot \mathrm{L}^{-1}$ ) throughout the day showed that ad libitum fluid intake decreased by approximately $43 \%$ compared with the control group of water supplementation. ${ }^{34}$ Although volume was lower, and thus percent dehydration was greater, in the electrolyte group, both groups exhibited similar thermoregulatory strain and work output throughout the 15 -h shift. ${ }^{34}$ This suggests that palatability can alter fluid ingestion but under different circumstances may or may not risk hydration. Together, these data imply that due to the large individual variability in fluid volume and sodium losses through sweat, environmental influences, and taste preference, the customization of optimal fluid replacement strategies is important to achieve maximal benefits with minimal cost. ${ }^{11}$ This knowledge may be useful when considering optimal fluid replacement strategies concurrent with exercise in the heat.

Metabolically, the effect of the 2 beverages altered substrate utilization (Figure 5). SDS has a greater $\mathrm{CHO}$ content $(5.9 \%$, or a total of approximately $80 \mathrm{~g}$ ) compared with ORS (3.4\%, or a total of approximately $46 \mathrm{~g}$ ), which appeared to elevate $\mathrm{CHO}$ oxidation in both SDS and ORS, although this did not reach a significant treatment effect (Figure 5A). Perhaps inversely related, fat oxidation was significantly lower post-exercise in SDS (Figure 5B). $\mathrm{CHO}$ delivery has been shown to attenuate the increase in fat oxidation during continuous exercise. ${ }^{35,36}$

Exercising in the heat can also alter fuel utilization by upregulating the reliance on stored $\mathrm{CHO}$ because greater skin blood flow may jeopardize fat oxidation. ${ }^{37-39}$ Consistent with this, the current study found that $\mathrm{CHO}$ oxidation increased in both treatment groups over time (Figure 5A). Despite this elevation of CHO oxidation over time, both ORS and SDS showed increased blood glucose concentrations from pre- to post-exercise (Figure 4). Typically, the delivery of CHO-containing beverages during exercise results in the maintenance, not elevation, of blood glucose. ${ }^{40}$ This may be in part explained by the stress of exercising in the heat. Although the exercise was designed at $50 \%$ of $\mathrm{VO}_{2 \max }$, cardiovascular drift in the heat resulted in a HR of $>170$ beats $\min ^{-1}$ and RPE of approximately 15 by the end of exercise, suggesting significant sympathetic stimulation. Thus, heat-induced sympathetic stimulation of hepatic glucose output may have contributed to the rise in blood glucose during exercise. ${ }^{41}$
A treatment difference was not significant until after exercise during the 30-min rest period, where blood glucose was higher post-trial in subjects who received SDS (Figure 4). At the same time, RPE also demonstrated a treatment difference, with ORS resulting in higher perceived effort. The attenuation of RPE during exercise when provided $\mathrm{CHO}$ is consistent with the literature. ${ }^{40,42}$

Additionally, exogenous $\mathrm{CHO}$ ingestion has been shown to provide an ergogenic effect during prolonged performance in both laboratory ${ }^{16,40,42}$ and field studies. ${ }^{43,44}$ Although the work of WLFF appears to be lowto moderate-intensity exercise, ${ }^{18}$ supplemental liquid CHO $\left(40 \mathrm{~g} \cdot \mathrm{h}^{-1}\right)$ resulted in a $20 \%$ increase in work productivity throughout the day. ${ }^{43}$ The greatest benefit of CHO supplementation was found during the latter hours of the workday. ${ }^{43}$ The use of $\mathrm{CHO}$ as an ergogenic aid for WLFF may be beyond work output because safety is an important concern in the latter hours of the workday when fatigue sets in, especially in areas where lateafternoon heat increases. Another study using militaryspecific tasks showed that soldiers who consumed a CHO-electrolyte beverage $(+2800 \mathrm{kcal}$ CHO over 3 days) increased both uphill run performance and had improved marksmanship compared with placebo. ${ }^{44}$ Together with the current study, these data suggest that CHO ingestion, such as found in SDS, improves performance in occupational athletes.

\section{Conclusions}

In this study, we found that the nearly 3-fold greater sodium in ORS compared with SDS did not result in differences in fluid balance during exercise in the heat while wearing WLFF personal protective equipment. This suggests that the antidiuresis while exercising in the heat negates the subtle differences between the ORS and SDS composition. Thus, under these conditions, drink volume, and not composition, may be more important in maintaining fluid balance.

Additionally, both drinks elevated blood glucose; however, SDS resulted in better maintenance of blood glucose at the end of the 2-h trials. This may become important in situations of limited $\mathrm{CHO}$ availability and longer duration work, such as in sports or the WLFF. Together, these data contribute to the practice of individualizing fluid amount and content on the basis of specific situations (e.g., environment, acclimatization, energy expenditure, and body size) to optimize fluid homeostasis. ${ }^{11,17}$

Acknowledgments: The authors thank the subjects for their time and energy in their volunteer effort. This study would not have been possible without Kansas Suenram, Keagan Shillington, Micah Drew, Brittany Hanser, Julia Guilliams, Thane Thompson, Lindsey Eagleman, 
and Manuel Dote Montero as research assistants in data collection. This study was supported by the US Forest Service (14-CR-11138200-009).

Author Contributions: Study concept, design, data acquisition and analysis, and writing and revision of the manuscript (MWS, CLD).

Financial/Material Support: None.

Disclosures: None.

\section{References}

1. Armstrong LE, Costill DL, Fink WJ. Influence of diureticinduced dehydration on competitive running performance. Med Sci Sports Exerc. 1985;17(4):456-61.

2. Casa DJ, Stearns RL, Lopez RM, DeMartini JK, Pagnotta KD, Ruiz RC, et al. Influence of hydration on physiological function and performance during trail running in the heat. J Athl Train. 2010;45(2):147-56.

3. Ely BR, Cheuvront SN, Kenefick RW, Sawka MN. Aerobic performance is degraded, despite modest hyperthermia, in hot environments. Med Sci Sports Exerc. 2010;42(1):135-41.

4. Goulet ED. Effect of exercise-induced dehydration on endurance performance: Evaluating the impact of exercise protocols on outcomes using a meta-analytic procedure. $\mathrm{Br}$ J Sports Med. 2013;47(11):679-86.

5. Montain SJ, Coyle EF. Influence of graded dehydration on hyperthermia and cardiovascular drift during exercise. J Appl Physiol. 1992;73(4):1340-50.

6. Sawka MN, Burke LM, Eichner ER, Maughan RJ, Montain SJ, Stachenfeld NS. American College of Sports Medicine position stand. Exercise and fluid replacement. Med Sci Sports Exerc. 2007;39(2):377-90.

7. González-Alonso J, Mora-Rodríguez R, Below PR, Coyle EF. Dehydration markedly impairs cardiovascular function in hyperthermic endurance athletes during exercise. J Appl Physiol. 1997;82(4):1229-36.

8. European Food and Safety Authority (EFSA) Panel on Dietetic Products, Nutrition, and Allergies. Scientific opinion on dietary reference values for water. EFSA J. 2010;(8):1459.

9. Shirreffs SM, Taylor AJ, Leiper JB, Maughan RJ. Postexercise rehydration in man: Effects of volume consumed and drink sodium content. Med Sci Sports Exerc. 1996;28 (10):1260-71.

10. Takamata A, Mack GW, Gillen CM, Nadel ER. Sodium appetite, thirst, and body fluid regulation in humans during rehydration without sodium replacement. Am J Physiol. 1994;266:1493-502.

11. Baker LB, Jeukendrup AE. Optimal composition of fluid-replacement beverages. Compr Physiol. 2014;4(2): 575-620.

12. Wemple RD, Morocco TS, Mack GW. Influence of sodium replacement on fluid ingestion following exercise-induced dehydration. Int J Sport Nutr. 1997;7(2):104-16.

13. Atia AN, Buchman AL. Oral rehydration solutions in noncholera diarrhea: A review. Am J Gastroenterol. 2009;104 (10):2596-604.
14. Blum LS, Oria PA, Olson CK, Breiman RF, Pavani K. Examining the use of oral rehydration salts and other oral rehydration therapy for childhood diarrhea in Kenya. Am J Trop Med Hyg. 2011;85(6):1126-33.

15. World Health Organization; Department of Child and Adolescent Health, Oral Rehydration Salts; Production of the new ORS. Unicef Geneva, Switzerland: WHO; 2014.

16. Cermak NM, van Loon LJ. The use of carbohydrates during exercise as an ergogenic aid. Sports Med. 2013;43 (11):1139-55.

17. Maughan RJ, Watson P, Corgery PA, Walsh NP, Oliver $\mathrm{SJ}$, Dolci A, et al. A randomized trial to assess the potential of different beverages to affect hydration status: development of a beverage hydration index. Am J Clin Nutr. 2016;103(3):717-23.

18. Cuddy JS, Sol JA, Hailes WS, Ruby BC. Work patterns dictate energy demands and thermal strain during wildland firefighting. Wilderness Environ Med. 2015;26(2):221-6.

19. Ruby BC, Shriver TC, Zderic TW, Sharkey BJ, Burks C, Tysk S. Total energy expenditure during arduous wildfire suppression. Med Sci Sports Exerc. 2002;34(6):1048-54.

20. Ruby BC, Schoeller DA, Sharkey BJ, Burks C, Tysk S. Water turnover and changes in body composition during arduous wildfire suppression. Med Sci Sports Exerc. 2003;35(10):1760-5.

21. Borg GA. Psychophysical bases of perceived exertion. Med Sci Sports Exerc. 1982;14(5):377-81.

22. Boren HG, Kory RC, Syner JC. The Veterans Administration-Army cooperative study of pulmonary function: II. The lung volume and its subdivisions in normal men. Am J Med. 1966;41(1):96-114.

23. Siri WE. Body Composition From Fluid Space and Density. Washington DC: National Academy of Sciences; 1961.

24. Bruce RA, Kusumi F, Hosmer D. Maximal oxygen intake and nomographic assessment of functional aerobic impairment in cardiovascular disease. Am Heart J. 1973;85 (4):546-62.

25. Dill DB, Costill DL. Calculation of percentage changes in volumes of blood, plasma, and red cells in dehydration. J Appl Physiol. 1974;37(2):247-8.

26. Mitchell JW, Nadel ER, Stolwijk JA. Respiratory weight losses during exercise. J Appl Physiol. 1972;32(4):474-6.

27. Jeukendrup AE, Jentjens R. Oxidation of carbohydrate feedings during exercise by means of gas exchange measurements. Int J Sports Med. 2000;29(6):407-24.

28. Earhart EL, Weiss EP, Rahman R, Kelly PV. Effects of oral sodium supplementation on indices of thermoregulation in trained, endurance athletes. J Sports Sci Med. 2015;14(1):172-8.

29. James LJ, Mears SA, Shirreffs SM. Electrolyte supplementation during severe energy restriction increases exercise capacity in the heat. Eur J Appl Physiol. 2015;115 (12):2621-9.

30. Maresh CM, Gabaree-Boulant CL, Armstrong LE, Judelson DA, Hoffman JR, Castellani JW, et al. Effect of hydration status on thirst, drinking, and related 
hormonal responses during low-intensity exercise in the heat. J Appl Physiol. 2004;97(1):39-44.

31. Montain SJ, Lair JE, Latzka WA, Sawka MN. Aldosterone and vasopressin response in the heat: hydration level and exercise intensity effects. Med Sci Sports Exerc. 1997;29 (5):661-8.

32. Baker LB, Barnes KA, Anderson ML, Passe DH, Stofan JR. Normative data for regional sweat sodium concentration and whole-body sweating rate in athletes. J Sports Sci. 2016;34(4):358-68.

33. Lara B, Gallo-Salazar C, Puente C, Areces F, Salinero JJ, Del Coso J. Interindividual variability in sweat electrolyte concentration in marathoners. J Int Soc Sports Nutr. 2016;13:31.

34. Cuddy JS, Ham JA, Harger SG, Slivka DR, Ruby BC. Effects of an electrolyte additive on hydration and drinking behavior during wildfire suppression. Wilderness Environ Med. 2008;19(3):172-80.

35. Cluberton LJ, McGee SL, Murphy RM, Hargreaves M. Effect of carbohydrate ingestion on exercise-induced alterations in metabolic gene expression. J Appl Physiol. 2005;99(4):1359-63.

36. Coyle EF, Coggan AR, Hemmert MK, Ivy JL. Muscle glycogen utilization during prolonged strenuous exercise when fed carbohydrate. J Appl Physiol. 1986;61(1): $165-72$.
37. Dumke CL, Slivka DR, Cuddy JS, Hailes WS, Ruby BC. Skeletal muscle metabolic gene response to carbohydrate feeding during exercise in the heat. J Int Soc Sports Nutr. 2013;10(1):40.

38. Febbraio MA, Snow RJ, Stathis CG, Hargreaves M, Carey MF. Effect of heat stress on muscle energy metabolism during exercise. J Appl Physiol. 1994;77(6):2827-31.

39. Hargreaves M, Angus D, Howlett K, Conus NM, Febbraio M. Effect of heat stress on glucose kinetics during exercise. J Appl Physiol. 1996;81(4):1594-7.

40. Jeukendrup AE, Moseley L, Mainwaring GI, Samuels S, Perry S, Mann CH. Exogenous carbohydrate oxidation during ultra endurance exercise. J Appl Physiol. 2006;100 (4):1134-41.

41. Kjaer M. Hepatic glucose production during exercise. Adv Exp Med Biol. 1998;441:117-27.

42. Carter J, Jeukendrup AE, Mundel T, Jones DA. Carbohydrate supplementation improves moderate and high-intensity exercise in the heat. Pflugers Arch. 2003;446(2):211-9.

43. Cuddy JS, Gaskill SE, Sharkey BJ, Harger SG, Ruby BC. Supplemental feedings increase self-selected work output during wildfire suppression. Med Sci Sports Exerc. 2007;39(6):1004-12.

44. Montain SJ, Shippee RL, Tharion WJ. Carbohydrate-electrolyte solution effects on physical performance of military tasks. Aviat Space Environ Med. 1997;68(5):384-91. 